\title{
Ascorbic acid, corticosteroids, and thiamine in sepsis: a review of the biologic rationale and the present state of clinical evaluation
}

\author{
Ari Moskowitz', Lars W. Andersen,2,3, David T. Huang ${ }^{5,6}$, Katherine M. Berg ${ }^{1}$, Anne V. Grossestreuer ${ }^{2}$, Paul E. Marik, \\ Robert L. Sherwin ${ }^{8}$, Peter C. Hou ${ }^{9}$, Lance B. Becker ${ }^{10,11}$, Michael N. Cocchi ${ }^{2,12}$, Pratik Doshi ${ }^{13}$, Jonathan Gong ${ }^{14}$, \\ Ayan $\operatorname{Sen}^{15}$ and Michael W. Donnino ${ }^{1,2,16^{*}}$
}

\begin{abstract}
The combination of thiamine, ascorbic acid, and hydrocortisone has recently emerged as a potential adjunctive therapy to antibiotics, infectious source control, and supportive care for patients with sepsis and septic shock. In the present manuscript, we provide a comprehensive review of the pathophysiologic basis and supporting research for each element of the thiamine, ascorbic acid, and hydrocortisone drug combination in sepsis. In addition, we describe potential areas of synergy between these therapies and discuss the strengths/weaknesses of the two studies to date which have evaluated the drug combination in patients with severe infection. Finally, we describe the current state of current clinical practice as it relates to the thiamine, ascorbic acid, and hydrocortisone combination and present an overview of the randomized, placebo-controlled, multi-center Ascorbic acid, Corticosteroids, and Thiamine in Sepsis (ACTS) trial and other planned/ongoing randomized clinical trials.
\end{abstract}

Keywords: Thiamine, Ascorbic acid, Corticosteroids, Metabolic resuscitation, Sepsis

\section{Background}

Sepsis is a common and highly morbid condition with an estimated 1.7 million cases occurring in the United States each year, resulting in over 270,000 deaths [1]. Despite advances in critical care practices, sepsis remains the most common cause of death in non-cardiac intensive care units (ICUs) $[2,3]$. Even among sepsis patients who survive their hospital stay, residual organ dysfunction requiring ongoing treatment after discharge is common [4]. Despite this high level of mortality and morbidity, antibiotics and source control remain the only focused therapies for this condition [5]. In a small, retrospective observational study of septic ICU patients, the combination of thiamine (200 $\mathrm{mg}$ every $12 \mathrm{~h}$ ), ascorbic acid (1500 mg every $6 \mathrm{~h}$ ), and hydrocortisone (50 mg every $6 \mathrm{~h}$ ) was associated with a dramatic improvement in organ injury, time to shock

\footnotetext{
* Correspondence: mdonnino@bidmc.harvard.edu;

amoskowi@bidmc.harvard.edu

${ }^{1}$ Beth Israel Deaconess Medical Center, Department of Medicine, Division of Pulmonary, Critical Care, and Sleep Medicine, Boston, MA, USA

${ }^{2}$ Beth Israel Deaconess Medical Center, Department of Emergency Medicine, Boston, MA, USA

Full list of author information is available at the end of the article
}

reversal, and mortality as compared to historical controls at the same hospital [6]. Each component of this combination of therapies has been recently evaluated individually in septic shock patients. A prior pilot randomized trial found that the provision of thiamine to septic shock patients with elevated lactate attenuated organ dysfunction (particularly renal dysfunction) and reduced lactate levels and potentially mortality in those patients with baseline thiamine deficiency $[7,8]$. In addition, two small randomized trials of ascorbic acid vs placebo in sepsis have demonstrated improved clinical outcomes $[9,10]$. Finally, while there have been mixed results with respect to the benefit of corticosteroids in septic shock generally $[11,12]$, the addition of corticosteroids to ascorbic acid may have a synergistic effect [6, 13-15].

In the present article, we review the biologic basis for and existing data supporting the use of thiamine, ascorbic acid, and corticosteroids in sepsis. We discuss the use of this drug combination in current clinical practice and the rationale for the currently enrolling Ascorbic Acid, Corticosteroids, and Thiamine in Sepsis (ACTS) trial, as well as other clinical trials addressing this question. 


\section{Organ dysfunction in sepsis}

The traditional paradigm of organ dysfunction in sepsis has focused on decreased systemic vascular resistance resulting in decreased organ perfusion, and ultimately impaired oxygen delivery [16-18]. Numerous studies, however, have shown that organ dysfunction can occur during sepsis and septic shock even in the absence of decreased perfusion [19-21]. Notably, histopathologic analyses of organs following death from sepsis often fail to demonstrate any substantial amount of ischemic injury, but rather reveal remarkably preserved parenchyma or a predominant pattern of apoptosis, suggesting alternative mechanisms of organ dysfunction apart from hypoperfusion and independent of cellular oxygen delivery [21-23]. A number of such mechanisms have been proposed and include mitochondrial dysfunction with resultant bioenergetic failure, a direct effect of the immune response to infection (related to pathogen-associated and damage-associated molecular patterns), microvascular abnormalities, endothelial dysfunction, and inter-organ cross-talk [24, 25].

\section{Thiamine, ascorbic acid, and corticosteroids}

The current management of sepsis and septic shock largely focuses on improving oxygen delivery via a combination of intravenous fluid and vasoactive medications while treating the infection with antibiotics and source control [5]. The combination of thiamine, ascorbic acid, and corticosteroids has been suggested as a potential adjunctive therapy targeted at non-oxygen delivery-dependent mechanisms of organ dysfunction (see Fig. 1 for a summary of suggested mechanisms).

\section{Thiamine}

Thiamine (vitamin B1) is a water-soluble vitamin that is a key component of a number of cellular metabolic processes. In its phosphorylated form, thiamine pyrophosphate, thiamine acts as a cofactor for pyruvate dehydrogenase, the enzyme necessary for converting pyruvate to acetyl-coenzyme A for entry into the Krebs cycle. When thiamine levels are insufficient, pyruvate is unable to be converted to acetyl coenzyme A, resulting in impaired aerobic respiration and a compulsory shift to the anaerobic pathway, resulting in elevated serum lactate levels [26-28]. Thiamine also plays a role in the metabolism of branched-chain amino acids and is a critical component of the pentose phosphate pathway, which is essential for the generation of NADPH and therefore glutathione cycling, an important anti-oxidant pathway [29-31]. A thiamine deficiency syndrome, beriberi, bears a number of similarities to sepsis, including peripheral vasodilation, cardiac dysfunction, and elevated lactate levels [29].

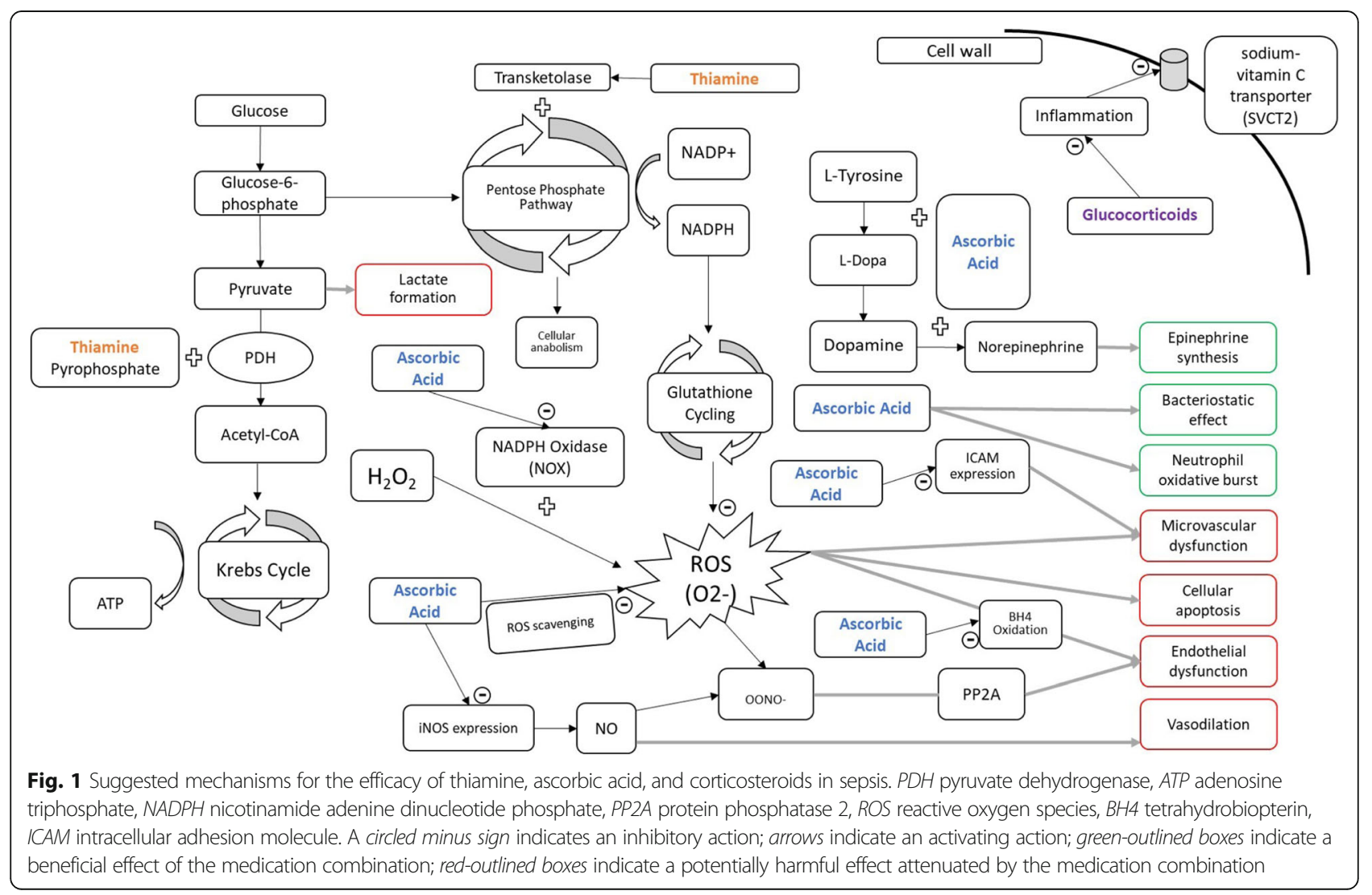


Thiamine deficiency is not rare in critically ill populations and may be associated with increased mortality in some cases [7, 29, 32, 33]. Further, thiamine levels are depleted during the course of critical illness and the administration of thiamine during critical illness may improve organ dysfunction [34-36]. In a mouse model of cardiac arrest, the provision of thiamine improved mitochondrial function, reduced histologic signs of brain injury, and improved neurologic outcomes [37]. In a canine model of septic shock, thiamine pyrophosphate improved lactate clearance, oxygen consumption, and arterial pressure irrespective of thiamine deficiency status [38]. In the only randomized trial of thiamine in human septic shock, 88 patients were selected for increased risk of symptomatic thiamine deficiency based on a serum lactate $>3 \mathrm{mmol} / \mathrm{L}$ after volume resuscitation. In that study, there was no effect overall of thiamine on the primary outcome of median lactate level at $24 \mathrm{~h}$, though there was a statistically significant difference when evaluating lactate levels at serial timepoints in the first $72 \mathrm{~h}$. In a pre-defined subgroup of patients with thiamine deficiency (35\% of the cohort), however, the administration of thiamine reduced lactate levels and improved mortality [7]. In a post hoc analysis of that study, patients without baseline end-stage renal disease who were given thiamine had better renal outcomes than those randomized to placebo [8]. Thiamine supplementation has not been shown to be associated with significant adverse effects, even at high doses [39]. Overall, these results suggest a role for thiamine supplementation as a low-risk and potentially high reward intervention for some patients with septic shock and increased baseline risk of thiamine deficiency.

\section{Ascorbic acid}

Like thiamine, ascorbic acid is a water-soluble vitamin essential for a number of processes in the human body. As an anti-oxidant, ascorbic acid is an electron donor that directly scavenges free radicals, prevents the generation of new free radicals through its suppressive effects on the NADPH oxidase (NOX) pathway, and assists in the recycling of other anti-oxidants [40-42]. The anti-oxidant effect of ascorbic acid results in reduced endothelial permeability, improved microvascular and macrovascular function, and attenuated cellular apoptosis in pathological states [41, 43, 44]. In addition, ascorbic acid has a number of effects on the immune system, including regulation of macrophage function, reduction of inflammatory mediators, and even a direct bacteriostatic effect at high concentrations [45-47]. Lastly, ascorbic acid is essential in the generation of endogenous vasopressors and may be important in maintaining vascular vasopressor responsiveness [41, 48].

Prior studies have found that plasma and cellular levels of ascorbic acid decline rapidly during critical illness
[49-51]. Similar to thiamine, ascorbic acid deficiency syndrome (scurvy) bears a number of similarities to sepsis, including malaise, coagulation abnormalities, and endothelial wall breakdown [49]. While interest in ascorbic acid for the management of critical illness has recently been reinvigorated, it is not new. The potential benefit of ascorbic acid for reducing resuscitation fluid requirements in burn patients and organ dysfunction in critically ill surgical patients was suggested over a decade ago [52, 53]. More recently, small randomized trials in sepsis have shown promise. In one study, 24 septic patients were randomized in a 1:1:1 ratio to receive high dose ascorbic acid $(200 \mathrm{mg} / \mathrm{kg})$, low dose ascorbic acid $(50 \mathrm{mg} / \mathrm{kg})$, or placebo. In that study, no adverse effects were related to the ascorbic acid and patients who received ascorbic acid had more rapid reduction in measures of organ injury, inflammation, and procalcitonin. There also appeared to be a dose-response relationship, with patients who received higher dose ascorbic acid having more rapid clinical improvement [9]. In a more recent study, 28 patients with vasopressor-dependent septic shock were randomized to $25 \mathrm{mg} / \mathrm{kg}$ of ascorbic acid every $6 \mathrm{~h}$ or placebo [10]. Those in the ascorbic acid arm required lower vasopressor doses and had lower mortality.

While the high doses of ascorbic acid given in the above clinical studies were not associated with any identified harms specific to the drug, one theoretical concern regarding the routine use of ascorbic acid in sepsis is the potential for increased oxalate excretion and the development of oxalate renal calculi [54]. Thiamine pyrophosphate is a key co-enzyme necessary for the function of glyoxylate aminotransferase, which catalyzes the breakdown of glyoxalate to carbon dioxide instead of oxalate. Thiamine deficiency states, therefore, may predispose to increased oxalate excretion $[54,55]$. It should be further noted that short-term, intravenous ascorbic acid-even at high doses-has not been found to increase the risk of renal calculi in controlled trials to date $[41,43]$. Other potential adverse effects of vitamin $\mathrm{C}$ include abdominal pain/bloating, increased iron absorption, hemolysis in patients with G6PD enzyme deficiency, and false negative results on fecal occult blood testing [56]. At very high doses, ascorbic acid may act as a pro-oxidant, although this has not been found to be the primary effect in vivo [41, 57]. Finally, high doses of ascorbic acid may falsely elevate glucose level readings when measured with certain point-of-care glucometers employing glucose dehydrogenase-pyrroloquinoline quinone amperometric methods [58].

\section{Corticosteroids and ascorbic acid}

A number of large, randomized trials have assessed the added benefit of corticosteroids when included as part of general septic shock management. These studies have generally shown corticosteroids to improve various clinical outcomes in septic shock (e.g., time to shock reversal, 
ventilator-free days), but there have been mixed results with respect to mortality [59-62]. Whether the routine administration of hydrocortisone to patients with septic shock should be standard remains a matter of debate $[11,12]$.

The biologic basis for the inclusion of hydrocortisone in the drug combination, however, is based on potential synergy between ascorbic acid and hydrocortisone. Glucocorticoid binding to glucocorticoid receptors is negatively affected by oxidizing molecules. This may be reversed by the administration of ascorbic acid, which has been shown to restore glucocorticoid receptor function [13]. The cellular uptake of ascorbic acid is mediated by the sodium-vitamin $\mathrm{C}$ transporter (SVCT2), which is downregulated during inflammatory states. The administration of glucocorticoids has been shown to increase expression of the transporter $[14,15]$. In a study examining the barrier function of human lung microvascular epithelial cells, the combination of ascorbic acid and hydrocortisone showed a synergistic barrier-protective effect after lipopolysaccharide exposure-above the combined effect of either agent when given alone [15].

\section{Thiamine, ascorbic acid, and corticosteroids}

The combination of thiamine, ascorbic acid, and corticosteroids has been studied in two, single center, before-and-after cohort studies [6,63]. In addition to the above-referenced study by Marik et al, a recent study performed in South Korea compared 53 patients with severe pneumonia admitted to the ICU who received the thiamine, ascorbic acid, and hydrocortisone combination to historical controls. In that study, patients who received the thiamine, ascorbic acid, and hydrocortisone combination had a substantial mortality benefit (adjusted odds ratio 0.15, 95\% CI 0.04-0.56). Although there were baseline imbalances in the 'control' and 'treatment' groups wherein patients in the 'treatment' group were more likely to have been receiving vasopressor and renal replacement therapy, the mortality benefit persisted after propensity-adjustment and propensity-matching. While these studies were the first to explore the drug combination in severe infection, their observational methodology, inclusion of non-consecutive and non-concurrent 'control' arms, small sample sizes, and single center nature represent significant limitations and preclude broad conclusions regarding the efficacy of this drug combination in sepsis.

\section{Ascorbic acid, corticosteroids, and thiamine for the treatment of sepsis in current practice}

As detailed above, scientific support for various elements of the thiamine, ascorbic acid, and hydrocortisone drug combination has existed for decades. Enthusiasm for this drug combination in sepsis has grown rapidly since 2016 due to the aforementioned paper by Marik et al. and the significant exposure it has received in both specialty medical blogs and the lay press [64-68]. Reactions in specialty medical blogs were mixed, with some physicians supporting the incorporation of the ascorbic acid, corticosteroids, and thiamine drug combination into routine sepsis management [66] and others arguing for more rigorous testing of the drug combination $[67,68]$. Arguments for more immediate uptake include the perceived low risk and relatively low cost of the intervention, biologic plausibility, and support from present literature, within the limitations that they represent. Arguments against include a long history of promising sepsis interventions that failed more rigorous scientific testing (e.g., activated protein $C$ [69]), the unknown safety profile of high-dose ascorbic acid in critically ill populations (and in combination with corticosteroids and thiamine), and a general concern regarding the generalizability of results from single center observational studies. At present, our discussions with critical care leaders at a number of academic and community centers have found that practice patterns are mixed, with some clinicians opting for routine administration of the drug combination, others only administering the drug combination in sepsis patients who are decompensating despite traditional management, and others who do not administer the drug combination at all.

\section{The Ascorbic Acid, Corticosteroids, and Thiamine in Sepsis (ACTS) trial and other ongoing clinical trials}

The lack of adequate data exemplified by mixed practice patterns suggests a state of scientific equipoise has developed regarding the risk/benefit ratio of the routine administration of ascorbic acid, corticosteroids, and thiamine in sepsis. Randomized clinical trials are urgently needed to assess the effect of this drug combination on clinically important outcomes in sepsis. As of July 1st, 2018, a review of the World Health Organization International Clinical Trials Registry Program (which includes clinicaltrials.gov) revealed nine ongoing or planned clinical trials of ascorbic acid, corticosteroids, and thiamine in six different countries (Table 1). These trials differ somewhat with respect to study populations (septic shock only vs sepsis or septic shock), control group interventions (the VITAMINS trial using hydrocortisone and the remainder choosing saline placebo), and primary outcomes, but all explore the intervention and daily doses proposed in the study by Marik et al [6]. Of note, the Vitamin C Infusion for Treatment in Sepsis Induced Acute Lung Injury (Citrus-ALI), a 170-patient trial of $200 \mathrm{mg} / \mathrm{kg} /$ day of ascorbic acid vs placebo in sepsis-induced acute lung injury, has completed enrollment, although results of this study are not yet available.

Our study, the Ascorbic Acid, Corticosteroids, and Thiamine in Sepsis (ACTS) Trial is a multi-center randomized clinical trial in the United States aimed at assessing the effect of the drug combination on organ function and other outcomes in septic shock. The ACTS trial is coordinated by the Center for Resuscitation Science at Beth Israel Deaconess Medical Center (BIDMC) in Boston, MA, USA and is 
Table 1 Ongoing and planned clinical trials of thiamine, ascorbic acid, and corticosteroids, in sepsis

\begin{tabular}{|c|c|c|c|c|}
\hline Trial name & Trial identifier & Country & Population & Primary outcome \\
\hline $\begin{array}{l}\text { Ascorbic acid, Corticosteroids, and Thiamine } \\
\text { in Sepsis (ACTS) Trial }\end{array}$ & NCT03389555 & USA & Septic shock & Change in SOFA score \\
\hline Vitamin C, Thiamine and Steroids in Sepsis (VICTAS) & NCT03509350 & USA & $\begin{array}{l}\text { Sepsis with acute cardiovascular } \\
\text { or respiratory compromise }\end{array}$ & $\begin{array}{l}\text { Vasopressor- and } \\
\text { ventilator-free days }\end{array}$ \\
\hline $\begin{array}{l}\text { Hydrocortisone, Vitamin C, and Thiamine for the } \\
\text { Treatment of Sepsis and Septic Shock (HYVCTTSSS) }\end{array}$ & NCT03258684 & China & $\begin{array}{l}\text { Sepsis or septic shock } \\
\text { (Sepsis-3 Criteria) }\end{array}$ & Hospital mortality \\
\hline $\begin{array}{l}\text { The Effect of Vitamin C, Thiamine and Hydrocortisone on } \\
\text { Clinical Course and Outcome in Patients With Severe Sepsis } \\
\text { and Septic Shock }\end{array}$ & NCT03335124 & Slovenia & Severe sepsis or septic shock & Hospital mortality \\
\hline $\begin{array}{l}\text { Metabolic Resuscitation Using Ascorbic Acid, Thiamine, } \\
\text { and Glucocorticoids in Sepsis (ORANGES) }\end{array}$ & NCT03422159 & USA & Sepsis or septic shock & Hospital mortality \\
\hline $\begin{array}{l}\text { The Vitamin C, Hydrocortisone and Thiamine in Patients } \\
\text { With Septic Shock Trial (VITAMINS) }\end{array}$ & NCT03333278 & $\begin{array}{l}\text { Australia and } \\
\text { New Zealand }\end{array}$ & Septic shock & Vasopressor-free days \\
\hline $\begin{array}{l}\text { Evaluation of Hydrocortisone, Vitamin C and Thiamine } \\
\text { for the Treatment of Septic Shock (HYVITS) }\end{array}$ & NCT03380507 & Qatar & Septic shock & Hospital mortality \\
\hline Steroids, Thiamine, and Vitamin C in Septic Shock (STACSS) & $\begin{array}{l}\text { CTRI/2018/ } \\
04 / 013384\end{array}$ & India & Septic shock & Shock reversal \\
\hline $\begin{array}{l}\text { Thiamine, Vitamin C and Hydrocortisone in the Treatment } \\
\text { of Septic Shock }\end{array}$ & NCT03540628 & USA & Septic shock & $\begin{array}{l}\text { Mortality (as compared } \\
\text { to the study by } \\
\text { Marik et al. [6]) }\end{array}$ \\
\hline
\end{tabular}

currently enrolling. The trial is supported by the Open Philanthropy Project (https://www.openphilanthropy.org/). Patients are randomized in a $1: 1$ ratio to receive thiamine (100 mg), ascorbic acid (1500 mg), and hydrocortisone $(50 \mathrm{mg})$ or matching placebo four times daily for 4 days. The primary outcome is change in the Sequential Organ Failure Assessment (SOFA) score from baseline to $72 \mathrm{~h}$, with key secondary outcomes including the incidence of renal failure and 30-day mortality. The primary outcome of 72-h SOFA score was selected to reflect the anticipated beneficial effects of thiamine, ascorbic acid, and corticosteroids on organ function. As organ dysfunction is a defining element of sepsis and a major determinant of survival, this outcome is patient centered and the attenuation of organ dysfunction may be practice changing. Further, the SOFA score can be measured early in a patient's hospital course and is therefore less impacted by downstream elements of hospital care than overall mortality.

The ACTS trial, in combination with the other trials described above, may provide important validation of the results found by Marik et al. Should those results be replicated, the potential benefit in terms of lives saved world-wide annually from sepsis could be measured in the hundreds of thousands. Even if the results from Marik et al. are not replicated, the ACTS trial and other trials of thiamine, ascorbic acid, and corticosteroids will provide important scientific data regarding the effect of metabolic resuscitation in sepsis that may guide future studies in this area. Given concerns about reproducibility in science [70], replication of results in different patient populations is crucial to demonstrating a true, generalizable effect. The multiple ongoing trials testing this drug combination creates a rare scenario in critical care medicine research where multiple, independent investigators are exploring the effects of a single intervention in unique patient cohorts. Further, a prospectively planned patient-level metanalysis combining data from the ACTS trial and the VICTAS trial would provide increased power and an ability to better explore the effect of thiamine, ascorbic acid, and hydrocortisone in certain patient subgroups [71].

\section{Conclusions}

The combination of thiamine, ascorbic acid, and corticosteroids is a promising new therapy for sepsis resuscitation but currently lacks robust evidence to support its widespread use. The potential effectiveness of this medication combination is rooted in biologic plausibility and supported by small clinical trials of the various individual components. Randomized data to confirm or refute the observational evidence for the drug combination are needed, and several clinical trials are ongoing or planned in the near future. We therefore anticipate a timely answer to the question of whether thiamine, ascorbic acid, and corticosteroids will play a role in the evolution of sepsis therapies.

\section{Abbreviations}

ACTS: Ascorbic acid, Corticosteroids, and Thiamine in Sepsis; ICU: Intensive care unit; NOX: NADPH oxidase pathway; SOFA: Sequential organ failure assessment

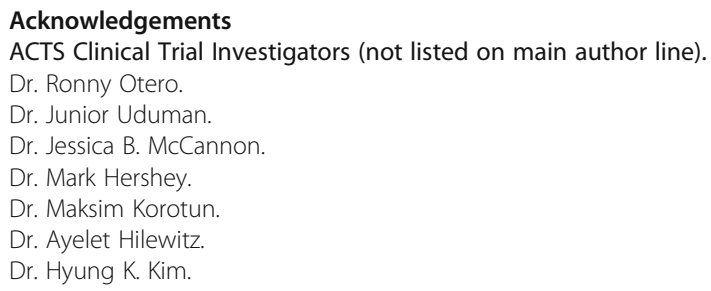




\section{Funding}

The ACTS trial is supported by a grant from the Open Philanthropy Project Dr. Cocchi is funded by a grant from the American Heart Association (15SDG22420010). Dr. Moskowitz and Dr. Berg are supported by grants from the National Institutes of Health (K23GM128005-01 \& 1K23HL128814-01, respectively). Dr. Grossestreuer is supported by a KL2/Catalyst Medical Research Investigator Training award (an appointed KL2 award) from Harvard Catalyst |The Harvard Clinical and Translational Science Center (National Center for Research Resources and the National Center for Advancing Translational Sciences, National Institutes of Health Award KL2 TR001100) Dr. Hou is supported by a grant from the National Institutes of Health (UO1HL122989-03).

\section{Availability of data and materials}

Data sharing is not applicable to this article as no datasets were generated or analyzed during the current study.

\section{Authors' contributions}

All authors made substantial contributions to the concept and design of the manuscript. Authors AM and MWD created the initial draft the manuscript, after which all authors provided critically important intellectual content and reviewed the final manuscript prior to submission. All authors read and approved the final manuscript.

\section{Ethics approval and consent to participate} Not applicable.

\section{Consent for publication}

Not applicable.

\section{Competing interests}

The authors are currently conducting the Ascorbic Acid, Corticosteroids, and Thiamine in Sepsis (ACTS) clinical trial.

\section{Publisher's Note}

Springer Nature remains neutral with regard to jurisdictional claims in published maps and institutional affiliations.

\section{Author details}

${ }^{1}$ Beth Israel Deaconess Medical Center, Department of Medicine, Division of Pulmonary, Critical Care, and Sleep Medicine, Boston, MA, USA. ${ }^{2}$ Beth Israel Deaconess Medical Center, Department of Emergency Medicine, Boston, MA, USA. ${ }^{3}$ Research Center for Emergency Medicine, Aarhus University Hospital, Aarhus, Denmark. ${ }^{4}$ Department of Anesthesiology, Aarhus University Hospital, Aarhus, Denmark. ${ }^{5}$ Department of Critical Care Medicine, University of Pittsburgh, Pittsburgh, PA, USA. ${ }^{6}$ Department of Emergency Medicine University of Pittsburgh, Pittsburgh, PA, USA. ${ }^{7}$ Department of Internal Medicine, Eastern Virginia Medical School, Norfolk, VA, USA. ${ }^{8}$ Department of Emergency Medicine, Wayne State University School of Medicine/Detroit Receiving Hospital, Detroit, MI, USA. ${ }^{9}$ Division of Emergency Critical Care Medicine, Department of Emergency Medicine, Brigham and Women's Hospital, Boston, MA, USA. ${ }^{10}$ Department of Emergency Medicine, Donald and Barbara Zucker School of Medicine at Hofstra/Northwell, Hempstead, NY, USA. ${ }^{11}$ Feinstein Institute for Medical Research, Manhasset, NY, USA.

${ }^{12}$ Department of Anesthesia Critical Care, Division of Critical Care, Beth Israel Deaconess Medical Center, Boston, MA, USA. ${ }^{13}$ Department of Emergency Medicine and Internal Medicine, University of Texas Health Science Center at Houston, Houston, TX, USA. ${ }^{14}$ Donald and Barbara Zucker School of Medicine at Hofstra/Northwell, Northwell Health System, New Hyde Park, NY, USA.

${ }^{15}$ Department of Critical Care Medicine, Mayo Clinic, Phoenix, AZ, USA. ${ }^{16}$ Beth Israel Deaconess Medical Center, Emergency Medicine, One Deaconess Rd, W/CC 2, Boston, MA 02215, USA.

\section{Received: 9 August 2018 Accepted: 3 October 2018}

Published online: 29 October 2018

\section{References}

1. Rhee C, Dantes R, Epstein L, Murphy DJ, Seymour CW, Iwashyna TJ, et al. Incidence and trends of sepsis in US hospitals using clinical vs claims data, 2009-2014. JAMA. 2017;318(13):1241-9.
2. Mayr FB, Yende S, Angus DC. Epidemiology of severe sepsis. Virulence. 2014 5(1):4-11.

3. Stevenson EK, Rubenstein AR, Radin GT, Wiener RS, Walkey AJ. Two decades of mortality trends among patients with severe sepsis: a comparative metaanalysis. Crit Care Med. 2014;42(3):625-31.

4. Alobaidi R, Basu RK, Goldstein SL, Bagshaw SM. Sepsis-associated acute kidney injury. Semin Nephrol. 2015;35(1):2-11.

5. Rhodes A, Evans LE, Alhazzani W, Levy MM, Antonelli M, Ferrer R, et al. Surviving Sepsis Campaign: international guidelines for management of sepsis and septic shock: 2016. Crit Care Med. 2017;45(3):486-552.

6. Marik PE, Khangoora V, Rivera R, Hooper MH, Catravas J. Hydrocortisone, vitamin $C$ and thiamine for the treatment of severe sepsis and septic shock: a retrospective before-after study. Chest. 2017;151(6):1229-38.

7. Donnino MW, Andersen LW, Chase M, Berg KM, Tidswell M, Giberson T, et al. Randomized, double-blind, placebo-controlled trial of thiamine as a metabolic resuscitator in septic shock: a pilot study. Crit Care Med. 2016; 44(2):360-7.

8. Moskowitz A, Andersen LW, Cocchi MN, Karlsson M, Patel PV, Donnino MW. Thiamine as a renal protective agent in septic shock. a secondary analysis of a randomized, double-blind, placebo-controlled trial. Ann Am Thorac Soc. 2017:14(5):737-41.

9. Fowler AA 3rd, Syed AA, Knowlson S, Sculthorpe R, Farthing D, DeWilde C, et al. Phase I safety trial of intravenous ascorbic acid in patients with severe sepsis. J Transl Med. 2014;12:32.

10. Zabet MH, Mohammadi M, Ramezani M, Khalili $\mathrm{H}$. Effect of high-dose Ascorbic acid on vasopressor's requirement in septic shock. J Res Pharm Pract. 2016;5(2):94-100.

11. Rochwerg B, Oczkowski SJ, Siemieniuk RAC, Agoritsas T, Belley-Cote E, D'Aragon F, et al. Corticosteroids in sepsis: an updated systematic review and meta-analysis. Crit Care Med. 2018;46(9):1411-20.

12. Rygard SL, Butler E, Granholm A, Moller MH, Cohen J, Finfer S, et al. Lowdose corticosteroids for adult patients with septic shock: a systematic review with meta-analysis and trial sequential analysis. Intensive Care Med. 2018:44(7):1003-16.

13. Okamoto K, Tanaka H, Makino Y, Makino I. Restoration of the glucocorticoid receptor function by the phosphodiester compound of vitamins $C$ and $E, E P C$ K1 (L-ascorbic acid 2-[3,4-dihydro-2,5,7,8-tetramethyl-2-(4,8,12-trimethyltridecyl)$2 \mathrm{H}-1$-benzopyran-6 -yl hydrogen phosphate] potassium salt), via a redoxdependent mechanism. Biochem Pharmacol. 1998;56(1):79-86.

14. Fujita I, Hirano J, Itoh N, Nakanishi T, Tanaka K. Dexamethasone induces sodium-dependant vitamin C transporter in a mouse osteoblastic cell line MC3T3-E1. Br J Nutr. 2001;86(2):145-9

15. Barabutis N, Khangoora V, Marik PE, Catravas JD. Hydrocortisone and ascorbic acid synergistically prevent and repair lipopolysaccharide-induced pulmonary endothelial barrier dysfunction. Chest. 2017;152(5):954-62.

16. Schrier RW, Wang W. Acute renal failure and sepsis. N Engl J Med. 2004; 351(2):159-69.

17. Landry DW, Oliver JA. The pathogenesis of vasodilatory shock. N Engl J Med. 2001:345(8):588-95.

18. Honore PM, Jacobs R, De Waele E, Diltoer M, Spapen HD. Renal blood flow and acute kidney injury in septic shock: an arduous conflict that smolders intrarenally? Kidney Int. 2016;90(1):22-4.

19. Legrand M, Dupuis C, Simon C, Gayat E, Mateo J, Lukaszewicz AC, et al. Association between systemic hemodynamics and septic acute kidney injury in critically ill patients: a retrospective observational study. Crit Care. 2013;17(6):R278.

20. Langenberg C, Bagshaw SM, May CN, Bellomo R. The histopathology of septic acute kidney injury: a systematic review. Crit Care. 2008;12(2):R38.

21. Maiden MJ, Otto S, Brealey JK, Finnis ME, Chapman MJ, Kuchel TR, et al. Structure and function of the kidney in septic shock. A prospective controlled experimental study. Am J Respir Crit Care Med. 2016;194(6):692-700.

22. Takasu O, Gaut JP, Watanabe E, To K, Fagley RE, Sato B, et al. Mechanisms of cardiac and renal dysfunction in patients dying of sepsis. Am J Respir Crit Care Med. 2013;187(5):509-17.

23. Kosaka J, Lankadeva YR, May CN, Bellomo R. Histopathology of septic acute kidney injury: a systematic review of experimental data. Crit Care Med. 2016; 44(9):e897-903.

24. Lelubre C, Vincent JL. Mechanisms and treatment of organ failure in sepsis. Nat Rev Nephrol. 2018;14(7):417-27.

25. Brealey D, Brand M, Hargreaves I, Heales S, Land J, Smolenski R, et al. Association between mitochondrial dysfunction and severity and outcome of septic shock. Lancet. 2002;360(9328):219-23. 
26. Manzanares W, Hardy G. Thiamine supplementation in the critically ill. Curr Opin Clin Nutr Metab Care. 2011;14(6):610-7.

27. Frank RA, Leeper FJ, Luisi BF. Structure, mechanism and catalytic duality of thiamine-dependent enzymes. Cell Mol Life Sci. 2007;64(7-8):892-905.

28. Andersen LW, Holmberg MJ, Berg KM, Chase M, Cocchi MN, Sulmonte C, et al. Thiamine as an adjunctive therapy in cardiac surgery: a randomized, double-blind, placebo-controlled, phase II trial. Crit Care. 2016;20:92.

29. Mallat J, Lemyze M, Thevenin D. Do not forget to give thiamine to your septic shock patient! J Thorac Dis. 2016;8(6):1062-6.

30. Gioda CR, de Oliveira Barreto T, Primola-Gomes TN, de Lima DC, Campos PP, Capettini Ldos S, et al. Cardiac oxidative stress is involved in heart failure induced by thiamine deprivation in rats. Am J Physiol Heart Circ Physiol. 2010;298(6):H2039-45

31. Pacal L, Tomandl J, Svojanovsky J, Krusova D, Stepankova S, Rehorova J, et al. Role of thiamine status and genetic variability in transketolase and other pentose phosphate cycle enzymes in the progression of diabetic nephropathy. Nephrol Dial Transplant. 2011;26(4):1229-36.

32. Cruickshank AM, Telfer AB, Shenkin A. Thiamine deficiency in the critically ill. Intensive Care Med. 1988;14(4):384-7.

33. Corcoran TB, O'Neill MA, Webb SA, Ho KM. Prevalence of vitamin deficiencies on admission: relationship to hospital mortality in critically ill patients. Anaesth Intensive Care. 2009;37(2):254-60.

34. Donnino MW, Carney E, Cocchi MN, Barbash I, Chase M, Joyce N, et al. Thiamine deficiency in critically ill patients with sepsis. J Crit Care. 2010;25(4):576-81.

35. Nuzzo E, Berg KM, Andersen LW, Balkema J, Montissol S, Cocchi MN, et al. Pyruvate dehydrogenase activity is decreased in the peripheral blood mononuclear cells of patients with sepsis. A prospective observational trial. Ann Am Thorac Soc. 2015;12(11):1662-6.

36. Donnino MW, Cocchi MN, Smithline H, Carney E, Chou PP, Salciccioli J. Coronary artery bypass graft surgery depletes plasma thiamine levels. Nutrition. 2010;26(1):133-6.

37. Ikeda K, Liu X, Kida K, Marutani E, Hirai S, Sakaguchi M, et al. Thiamine as a neuroprotective agent after cardiac arrest. Resuscitation. 2016;105:138-44.

38. Lindenbaum GA, Larrieu AJ, Carroll SF, Kapusnick RA. Effect of cocarboxylase in dogs subjected to experimental septic shock. Crit Care Med. 1989;17(10):1036-40.

39. Donnino MW, Vega J, Miller J, Walsh M. Myths and misconceptions of Wernicke's encephalopathy: what every emergency physician should know. Ann Emerg Med. 2007;50(6):715-21.

40. Mortensen A, Lykkesfeldt J. Does vitamin C enhance nitric oxide bioavailability in a tetrahydrobiopterin-dependent manner? In vitro, in vivo and clinical studies. Nitric Oxide. 2014;36:51-7.

41. Oudemans-van Straaten HM, Spoelstra-de Man AM, de Waard MC. Vitamin C revisited. Crit Care. 2014;18(4):460.

42. Wu F, Tyml K, Wilson JX. iNOS expression requires NADPH oxidasedependent redox signaling in microvascular endothelial cells. J Cell Physiol. 2008;217(1):207-14.

43. Amrein K, Oudemans-van Straaten HM, Berger MM. Vitamin therapy in critically ill patients: focus on thiamine, vitamin C, and vitamin D. Intensive Care Med. 2018.

44. KC S, Carcamo JM, Golde DW. Vitamin C enters mitochondria via facilitative glucose transporter 1 (Glut1) and confers mitochondrial protection against oxidative injury. FASEB J. 2005;19(12):1657-67.

45. Victor W, Guayerbas N, Puerto M, Medina S, De la Fuente M. Ascorbic acid modulates in vitro the function of macrophages from mice with endotoxic shock. Immunopharmacology. 2000;46(1):89-101.

46. Armour J, Tyml K, Lidington D, Wilson JX. Ascorbate prevents microvascular dysfunction in the skeletal muscle of the septic rat. J Appl Physiol. 2001; 90(3):795-803.

47. Carcamo JM, Pedraza A, Borquez-Ojeda O, Golde DW. Vitamin C suppresses TNF alpha-induced NF kappa B activation by inhibiting I kappa B alpha phosphorylation. Biochemistry. 2002;41(43):12995-3002.

48. Carr AC, Shaw GM, Fowler AA, Natarajan R. Ascorbate-dependent vasopressor synthesis: a rationale for vitamin $C$ administration in severe sepsis and septic shock? Crit Care. 2015;19:418

49. Marik PE, Hooper MH. Doctor-your septic patients have scurvy! Crit Care. 2018;22(1):23.

50. Wilson JX. Mechanism of action of vitamin C in sepsis: ascorbate modulates redox signaling in endothelium. BioFactors. 2009;35(1):5-13.

51. Carr AC, Rosengrave PC, Bayer S, Chambers S, Mehrtens J, Shaw GM. Hypovitaminosis C and vitamin C deficiency in critically ill patients despite recommended enteral and parenteral intakes. Crit Care. 2017;21(1):300.

52. Tanaka H, Matsuda T, Miyagantani Y, Yukioka T, Matsuda H, Shimazaki S. Reduction of resuscitation fluid volumes in severely burned patients using ascorbic acid administration: a randomized, prospective study. Arch Surg. 2000;135(3):326-31.

53. Nathens AB, Neff MJ, Jurkovich GJ, Klotz P, Farver K, Ruzinski JT, et al. Randomized, prospective trial of antioxidant supplementation in critically ill surgical patients. Ann Surg. 2002;236(6):814-22.

54. Marik PE. Vitamin C for the treatment of sepsis: the scientific rationale. Pharmacol Ther. 2018;189:63-70.

55. Hoppe B, Beck BB, Milliner DS. The primary hyperoxalurias. Kidney Int. 2009; 75(12):1264-71

56. Levine M, Rumsey SC, Daruwala R, Park JB, Wang Y. Criteria and recommendations for vitamin C intake. JAMA. 1999:281(15):1415-23.

57. Spoelstra-de Man AME, Elbers PWG, Oudemans-Van Straaten HM. Vitamin C: should we supplement? Curr Opin Crit Care. 2018;24(4):248-55.

58. Flannery AH, Bastin MLT, Magee CA, Bensadoun ES. Vitamin C in sepsis: when it seems too sweet, it might (literally) be. Chest. 2017;152(2):450-1.

59. Venkatesh B, Finfer S, Cohen J, Rajbhandari D, Arabi Y, Bellomo R, et al. Adjunctive glucocorticoid therapy in patients with septic shock. N Engl J Med. 2018;378(9):797-808

60. Annane D, Sebille V, Charpentier C, Bollaert PE, Francois B, Korach JM, et al. Effect of treatment with low doses of hydrocortisone and fludrocortisone on mortality in patients with septic shock. JAMA. 2002;288(7):862-71.

61. Annane D, Renault A, Brun-Buisson C, Megarbane B, Quenot JP, Siami S, et al. Hydrocortisone plus fludrocortisone for adults with septic shock. N Engl J Med. 2018;378(9):809-18.

62. Sprung CL, Annane D, Keh D, Moreno R, Singer M, Freivogel $K$, et al. Hydrocortisone therapy for patients with septic shock. N Engl J Med. 2008; 358(2):111-24

63. Kim W-Y, Jo E-J, Eom JS, Mok J, Kim M-H, Kim KU, et al. Combined vitamin $C$, hydrocortisone, and thiamine therapy for patients with severe pneumonia who were admitted to the intensive care unit: Propensity scorebased analysis of a before-after cohort study. J Crit Care. 2018;47:211-8.

64. Harris R. Doctor turns up possible treatment for deadly sepsis NPR2017. Updated 3/23/2017. Available from: http://www.npr.org/sections/ healthshots/2017/03/23/521096488/doctor-turns-up-possible-treatment-fordeadly-sepsis. Accessed June 182018.

65. Harris R. Did an IV cocktail of vitamins and drugs save this lumberjack from sepsis. National Public Radio; 2018. Podcast. https://www.npr.org/sections/ health-shots/2018/02/21/583845485/did-an-iv-cocktail-of-vitamins-anddrugs-save-this-lumberjack-from-sepsis. Accessed June 282018.

66. Farkas J. Metabolic sepsis resuscitation: the evidence behind vitamin C 2017 Available from: https://emcrit.org/pulmcrit/metabolic-sepsis-resuscitation/. Accessed June 302018.

67. Mallemat H. The Marik protocol: have we found a "cure" for severe sepsis and septic shock? 2017. Available from: http://rebelem.com/the-marik-protocol-havewe-found-a-cure-for-severe-sepsis-and-septic-shock/. Accessed June 282018.

68. Faust J. The skeptics guide to EM; 2017. Podcast. Available from: http:// thesgem.com/2017/04/sgem174-dont-believe-the-hype-vitamin-c-cocktailfor-sepsis/. Accessed June 282018

69. Ranieri VM, Thompson BT, Barie PS, Dhainaut JF, Douglas IS, Finfer S, et al. Drotrecogin alfa (activated) in adults with septic shock. N Engl J Med. 2012 ; 366(22):2055-64.

70. loannidis JP. Why most published research findings are false. PLoS Med. 2005;2(8):e124.

71. Reade MC, Delaney A, Bailey MJ, Harrison DA, Yealy DM, Jones PG, et al. Prospective meta-analysis using individual patient data in intensive care medicine. Intensive Care Med. 2010;36(1):11-21. 